\title{
PERBANDINGAN EFEKTIVITAS PEMBERIAN SILVER SULFADIAZINE DENGAN GEL LIDAH BUAYA (Aloe vera) 99\% PADA TIKUS PUTIH ( Rattus norvegicus $L$.) JANTAN GALUR WISTAR SEBAGAI PENGOBATAN LUKA BAKAR
}

\author{
Atika Rahmi ${ }^{1}$, Ratih Yulistika Utami², Hervina ${ }^{3}$, Humairah Medina Liza Lubis \\ ${ }^{1}$ Fakultas Kedokteran Universitas Muhammadiyah Sumatera Utara \\ ${ }^{2}$ Unit Pendidikan Kedokteran, Fakultas Kedokteran Universitas Muhammadiyah Sumatera Utara \\ Email: ratihyulistika@umsu.ac.id \\ ${ }^{3}$ Departemen Ilmu Kesehatan Kulit dan Kelamin, Fakultas Kedokteran Universitas \\ Muhammadiyah Sumatera Utara \\ ${ }^{4}$ Departemen Patologi Anatomi, Fakultas Kedokteran Universitas Muhammadiyah Sumatera Utara
}

\begin{abstract}
Introduction: Burn injury is a common cause of morbidity and mortality. Outcomes of morbidity and disability for deep burns patients still not improved. Many modalities for wound bed preparation was not satisfied. Aloe vera gel have been used as an antiinflammatory natural agent, for treatment many deseases. It has also been used in the traditional medicine of many cultures and said to be beneficial in the treatment of disorders such as burns Objective: To find out the comparison of the effectiveness of administration of silver sulfadiazine and aloe vera gel $99 \%$ as a treatment of burns in white rat (Rattus norvegicus L.) male Wistar strain. Methodology: The research used True Experiment method with "pretest-posttest with control group design" design Result: The results show that the $P$ value for aloe vera number is $<0.05$, and the $P$ value for Silver sulfadiazinee levels also showing <0.05. Conclusion: There is a difference in effectiveness of giving 99\% aloe vera gel as a treatment for burns in white rats (Rattus norvegicus L.) male Wistar strain.
\end{abstract}

Keywords: Burn Injury,Aloe Vera, Silver sulfadiazinee

\section{PENDAHULUAN}

Luka bakar itu sendiri merupakan luka yang terjadi akibat sentuhan permukaan tubuh dengan benda-benda yang menghasilkan panas (api secara langsung maupun tidak langsung, pajanan suhu tinggi dari matahari, listrik, maupun bahan kimia, air, dan lain-lain) atau zat-zat yang bersifat membakar (asam kuat dan basa kuat). Kedalaman kerusakan jaringan akibat luka bakar tergantung pada derajat panas sumber, penyebab dan lamanya kontak dengan tubuh penderita. Derajat keparahan luka bakar dibagi 3 yaitu luka bakar derajat 1 kerusakan terbatas pada lapisan epidermis (surperficial), luka bakar derajat 2 kerusakan meliputi epidermis dan sebagian dermis, dan derajat 3 kerusakan meliputi seluruh ketebalan kulit dan lapisan yang lebih dalam sampai mencapai jaringan subkutan, otot dan tulang. ${ }^{1}$

Terdapat terapi luka bakar dari segi medis yaitu kombinasi antibakteri berbasis topikal seperti Silver sulfadiazine (SSD), Moist Exposed Ointment (MEBO), Mafenid asetat dan 
lain-lain. Silver sulfadiazine (SSD) yang merupakan gold standard terapi topikal pada luka bakar. ${ }^{2}$

Walaupun telah ada obat-obatan topikal secara medis untuk luka bakar, masyarakat masih sering menggunakan obat-obatan non medis seperti tanaman herbal yang dipercaya dapat mempercepat proses penyembuhan luka. World Health Organization (WHO) juga merekomendasikan penggunaan obat tradisional termasuk herbal dalam pemeliharaan kesehatan masyarakat. ${ }^{3}$

Salah satu tanaman obat yang memiliki khasiat obat adalah lidah buaya (aloe vera). Ada lima kandungan utama yang terdapat dalam lidah buaya yaitu saponin, tanin, polifenol, glikoprotein, polisakarida yang dapat digunakan sebagai bahan dalam penyembuhan luka bakar. ${ }^{4}$

Menurut Departemen Kesehatan Replublik Indonesia 2013 prevalensi luka bakar di Indonesia sebesar 2,2\% dan telah mengalami penurunan sebesar $1.5 \%$ dibandingkan pada tahun 2008 (2.2\%). Provinsi dengan prevalensi tertinggi adalah Papua (2.0\%) dan Bangka Belitung (1.4\%). Prevalensi tertinggi terjadi pada usia $1-4$ tahun sebesar 1,5\%. Frekuensi kematian akibat luka bakar di negara dengan pendapatan rendah dan menengah sebelas kali lebih tinggi dibandingkan dengan negara dengan pendapatan tinggi. Berdasarkan data rekam medis RSUP Haji Adam Malik Medan, terdapat 353 kasus luka bakar pada tahun 2011-2014 dengan penyebab terbanyak adalah flame burn injury (174 kasus, 50,4\%). ${ }^{2}$

gel lidah buaya memiliki efek yang sangat baik pada fase proliferasi dan proses kontraksi luka, dimana hal ini berperan penting dalam memperkecil, memendekkan, dan mempersempit ukuran luka, dan juga lendir lidah buaya tidak hanya meningkatkan jumlah kolagen, tetapi juga meningkatkan koneksi transversal antar ikatan sehingga sebagai hasilnya mempercepat perbaikan luka. ${ }^{5,6,7}$

Berdasarkan hal tersebut maka penulis ingin membuktikan adakah perbedaan efektifitas pemberian gel lidah buaya (aloe vera) $99 \%$ sebagai pengobatan luka bakar pada tikus putih (Rattus norvegicus l.) jantan galur wistar dibandingkan dengan pemberian silver sulfadiazine.

\section{METODE PENELITIAN}

\section{Jenis Penelitian}

Penelitian menggunakan metode true experiment dengan rancangan "pretest-posttest with control group design" Dalam penelitian ini digunakan metode penelitian perbandingan kelompok kontrol group comparison) yaitu dengan pengukuran (observasi) yang dilakukan setelah kelompok perlakuan menerima program atau intervensi. Hewan coba yang digunakan adalah tikus jantan (Rattus norvegicus L.) sebanyak 33 ekor, dengan 9 tikus sebagai kelompok kontrol negatif, 9 tikus sebagai kelompok kontrol positif dengan Silver sulfadiazine, dan 9 tikus sebagai kelompok perlakuan dengan gel aloe vera (the seam jeju fresh aloe vera 99\%). Dengan 2 cadangan tikus pada kelompok kontrol negatif, 2 cadangan tikus pada kelompok kontrol positif, dan 2 cadangan tikus pada kelompok perlakuan. 
Setiap kelompok tikus yang telah dianestesi dengan menggunakan lidocain $2 \%$ dan dicukur bulu pada punggungnya, diberikan paparan luka bakar sepanjang $2 \mathrm{~cm}$ dengan kedalaman $0,1 \mathrm{~cm}$. Paparan luka bakar dilakukan dengan menggunakan plat tembaga ukuran $2 \times 1$ $\mathrm{cm}$ dengan ketebalan $0,1 \mathrm{~cm}$, yang dipanaskan dengan suhu $100^{\circ} \mathrm{C}$ selama 8 detik. Dari hari 0, kelompok kontrol negatif tidak diberikan perlakuan. Pada kelompok kontrol positif diberi Silver sulfadiazine, secara topikal satu kali sehari pada daerah luka bakar. Dan kelompok perlakuan diberikan olesan gel lidah buaya $99 \%$ dengan merek dagang the seam jeju fresh aloe vera 99\% sebanyak satu kali sehari. Luka bakar dibiarkan terbuka. ${ }^{8}$

Hari pertama kali tikus dilukai ditentukan sebagai hari nol (0) dan harihari berikutnya adalah 1, 7, dan 14 . Pengukuran luas permukaan luka bakar dilakukan pada hari ke-0 ,hari ke-1, hari ke-7, dan hari ke-14. Luas permukaan luka bakar yang diukur adalah panjang $\mathrm{x}$ lebar luka bakar. Pengukuran luas permukaan luka bakar menggunakan mistar

\section{Analisis Data}

Data yang diperoleh dari hasil penelitian selanjutnya diuji dengan mengguanakan program komputer, pengujian pertama dilakukan uji normalitas dengan uji Saphiro-Wilk dengan nilai $\mathrm{p}>0,05$, artinya data tersebut berdistribusi normal maka akan dilanjutkan dengan uji One Way Annova (Analysis of Variance).

Data yang didapatkan berdistribusi normal ( $\mathrm{p}>0,05)$ dan selanjutnya untuk mengetahui pengaruh pemberian gel lidah buaya 99\%, salep silver sulfadiazinee, dan kelompok tanpa perlakuan apapun pada tikus putih (Rattus norvegicus L.) jantan galur wistar yang diberi luka bakar maka dilakukan uji One Way Anova. Pada hasil uji One Way Anova didapatkan Sig. 0,000 $(\mathrm{p}<0,05)$, maka dapat disimpulkan bahwa terdapat perbedaan yang bermakna diluas permukaan luka bakar antara kelompok kontrol negatif, kelompok positif dan intervensi pada hari ke-14. Analisis data dilanjutkan dengan tujuan untuk mengetahui dua kelompok yang memiliki perbedaan luas permukaan luka bakar yang bermakna. Analisis tersebut menggunakan uji post hoc games-howell

\section{HASIL PENELITIAN}

Pada hari ke-0 dan ke-1 rata-rata luas permukaan luka bakar pada kelompok kontrol negatif, kelompok aloe vera 99\%, dan kelompok Silver sulfadiazine sama yaitu $2 \mathrm{~cm}^{2}$. Pada hari ke-7 rata-rata luas permukaan luka bakar pada kelompok kontrol negatif yaitu 1,98 $\mathrm{cm}^{2}$, pada kelompok aloe vera $99 \%$ 1,86 $\mathrm{cm}^{2}$, dan pada kelompok Silver sulfadiazine $1,80 \mathrm{~cm}^{2}$. Dan pada hari ke14 rata-rata luas permukaan luka bakar pada kelompok kontrol negatif yaitu 1,37 $\mathrm{cm}^{2}$, pada kelompok aloe vera $99 \% \quad 0,42$ $\mathrm{cm}^{2}$ dan pada kelompok Silver sulfadiazine $0,62 \mathrm{~cm}^{2}$. 
Tabel 4.2 Rerata Luas Permukaan Luka Bakar

\begin{tabular}{lccc}
\hline Hari & \multicolumn{3}{c}{ Rerata luas permukaan luka } \\
& \multicolumn{3}{c}{ bakar } \\
& $\begin{array}{c}\text { Kontrol } \\
\text { negatif }\end{array}$ & $\begin{array}{c}\text { Aloe } \\
\text { vera } \\
99 \%\end{array}$ & $\begin{array}{c}\text { Silver } \\
\text { sulfadiaz } \\
\text { ine }\end{array}$ \\
\hline $\begin{array}{l}\text { Hari } \\
\text { ke- 0 }\end{array}$ & $2 \mathrm{~cm}^{2}$ & $2 \mathrm{~cm}^{2}$ & $2 \mathrm{~cm}^{2}$ \\
Hari & $2 \mathrm{~cm}^{2}$ & $2 \mathrm{~cm}^{2}$ & $2 \mathrm{~cm}^{2}$ \\
ke- 1 & & & \\
Hari & $1,98 \mathrm{~cm}^{2}$ & 1,86 & $1,80 \mathrm{~cm}^{2}$ \\
ke- 7 & & $\mathrm{cm}^{2}$ & \\
Hari & $1,37 \mathrm{~cm}^{2}$ & 0,42 & $0,62 \mathrm{~cm}^{2}$ \\
ke- 14 & & $\mathrm{cm}^{2}$ & \\
\hline
\end{tabular}

Data yang diperoleh dari hasil penelitian selanjutnya diuji dengan mengguanakan program komputer, pengujian pertama dilakukan uji normalitas dengan uji Saphiro-Wilk dengan nilai $\mathrm{p}>0,05$, artinya data tersebut berdistribusi normal maka akan dilanjutkan dengan uji One Way Annova (Analysis of Variance).

Tabel 4.3 Uji Normalitas data

\begin{tabular}{lccc}
\hline \multirow{2}{*}{ Kelompok } & \multicolumn{3}{c}{ Shapiro-Wilk } \\
& Jumlah & Sig. & P \\
& & & \\
\hline Kontrol negatif & 9 & 0,083 & \\
Aloe Vera 99\% & 9 & 0,076 & $>0,05$ \\
$\begin{array}{l}\text { Silver } \\
\text { sulfadiazine }\end{array}$ & 9 & 0,053 & \\
\hline
\end{tabular}

Pada tabel di atas nilai Sig. untuk luka bakar menunjukkan angka >0,05, maka data di atas dinyatakan berdistribusi normal ( $p>0,05)$ dan selanjutnya untuk mengetahui pengaruh pemberian gel lidah buaya 99\%, salep silver sulfadiazinee, dan kelompok tanpa perlakuan apapun pada tikus putih (Rattus norvegicus L.) jantan galur wistar yang diberi luka bakar maka dilakukan uji One Way Anova. Pada hasil uji One Way Anova didapatkan Sig. 0,000 $(\mathrm{p}<0,05)$, maka dapat disimpulkan bahwa terdapat perbedaan yang bermakna diluas permukaan luka bakar antara kelompok kontrol negatif, kelompok positif dan intervensi pada hari ke-14. Analisis data dilanjutkan dengan tujuan untuk mengetahui dua kelompok yang memiliki perbedaan luas permukaan luka bakar yang bermakna. Analisis tersebut menggunakan uji post hoc gameshowell, dengan hasil berikut :

Tabel 4.4 Nilai Sig. Pada Uji Post Hoc

Perbedaa

n rerata Nilai $\mathrm{p} \quad$ Ket

\begin{tabular}{cccc}
\hline $\begin{array}{c}\text { Kontrol } \\
(-) \text { vs }\end{array}$ & & & \\
Aloe & $1,09^{*}$ & $<0,001$ & Signifikan \\
Vera & & & \\
$99 \%$ & & & \\
Kontrol & & & \\
$(-)$ vs & & & \\
Silver & $0,84^{*}$ & $<0,001$ & Signifikan \\
sulfadiazi \\
ne
\end{tabular}

Luka bakar 
Berdasarkan hasil di atas perbedaan luas permukaan luka bakar yang bermakna jika $p<0,05$. Dengan demikian kelompok yang memiliki perbedaan bermakna adalah luas permukaan luka bakar pada kelompok kontrol negatif vs kelompok kontrol positif dengan nilai $\mathrm{p}$ $<0,001$, kelompok kontrol negatif vs kelompok perlakuan karna $\mathrm{p}<0,001$, dan kelompok Silver sulfadiazine vs kelompok aloe vera 99\% $\mathrm{p}=0,009$.

\section{PEMBAHASAN}

Dari hasil penelitian ini ditemukan bahwa lidah buaya 99\% efektif untuk penyembuhan luka bakar sesuai dengan hasil uji post hoc yang menunjukkan ada perbedaan yang bermakna dari kelompok kontrol negatif dengan kelompok lidah buaya, dan kelompok Silver sulfadiazine dengan kelompok lidah buaya. Hal ini sesuai dengan penelitian bahwa ekstrak lidah buaya mempunyai efek penyembuhan luka pada luka insisi kulit kelinci. ${ }^{5}$

Pada penelitian dimana pemberian gel lidah buaya (Aloe vera) memiliki efek yang sangat baik pada fase proliferasi dan proses kontraksi luka, dan berperan penting dalam memperkecil, memendekkan, dan mempersempit ukuran jarak pinggir luka pada tikus wistar Lendir lidah buaya tidak hanya meningkatkan jumlah kolagen di situs luka, tetapi juga meningkatkan koneksi transversal antar ikatan sehingga mempercepat perbaikan. ${ }^{6}$

Hasil penelitian menunjukkan bahwa perlakuan kelompok lidah buaya mengalami penurunan panjang luka lebih cepat dibandingkan dengan kelompok perlakuan madu. Lidah buaya berperan dalam mempercepat proses penyembuhan luka. ${ }^{9}$

Tanaman lidah buaya berupa daun dan akarnya mengandung saponin dan flavonoid, di samping itu daunnya mengandung tanin dan polifenol . Saponin mempunyai kemampuan membunuh kuman atau mencegah pertumbuhan mikroorganisme yang bisa menimbulkan infeksi sehingga efektif untuk menyembuhkan luka terbuka dan bersifat antiseptik, sedangkan tanin dapat digunakan sebagai pencegahan terhadap infeksi luka karena mempunyai daya antiseptik, dapat menciutkan pori-pori kulit, memperkeras kulit, dan menghentikan pendarahan yang ringan. Flavonoid dan polifenol mempunyai aktivitas sebagai antiseptik dan mencegah kerusakan akibat oksidasi yang terjadi pada kosmetik dan bermanfaat untuk regenerasi jaringan. ${ }^{10}$

Pada penelitian sebelumnya diperoleh hasil bahwa pemberian lidah buaya menurunkan deteksi $\alpha$-SMA yang relatif tinggi bersamaan dengan penurunan infiltrasi inflamasi yang signifikan pada semua fase serta pengendapan serat kolagen lebih matang dan lebih halus dibandingkan dengan kelompok luka yang tidak diberi apapun. ${ }^{11}$

Pada penelitian kelompok perlakuan Aloe vera $99 \%$ terjadi penyempitan luas permukaan luka bakar lebih cepat dibandingkan Silver sulfadiazine pada hari ke-14 Hal ini berarti dengan pemberian aloe vera $99 \%$ juga efektif dari segi anti bakteria terhadap penyembuhan luka bakar. Hal ini sesuai dengan penelitian yang menyatakan bahwa lidah buaya efektif 
menghambat pertumbuhan bakteri dengan menentukan diameter zona hambat terhadap bakteri Eschericia coli dan Staphylococcus aureus. ${ }^{12}$

Hal ini disebabkan oleh adanya senyawa aktif antibakteri yang terkandung dalam lendir lidah buaya yaitu saponin. Pada penelitian yang dilakukan oleh Puteri menunjukan bahwa ektrak kulit daun lidah buaya memiliki aktivitas antibakteri terhadap Staphylococcus aureus dan Escherichia coli. ${ }^{13}$

Pemberian lidah buaya menunjukkan proses pembersihan dan fagositosis. Pemberian lidah buaya dapat dapat jumlah sel neutrofil secara signifikan karna senyawa yang terkandung di dalam aloe vera bersifat sebagai imunomodulator yang dapat meningkatkan leukosit seperti makrofag dan sel T. ${ }^{14}$

\section{KESIMPULAN}

Terdapat pengurangan ukuran luas permukaan luka bakar dengan pemberian gel aloe vera $99 \%$ pada tikus putih (Rattus norvegicus L.) jantan galur wistar. Dan pemberian gel lidah buaya 99\% secara topikal lebih efektif terhadap pengecilan luas permukaan luka bakar dibandingkan pemberian salep silver sulfadiazine maupun tanpa pemberian apapun.

\section{REFERENSI}

1. Noer, M.S. Penanganan luka bakar akut. In Noer, M.S. (eds) "Penanganan luka bakar". Surabaya: Airlangga University Press; 2006. p: 3-5.
2. Maulana, R.A. "Faktor resiko yang berperan pada mortalitas penderita luka bakar rawat inap di RSUPH Adam Malik". Medan. Tesis. Fakultas Kedokteran Universitas Sumatera Utara. Medan; 2014. p: 110.

3. WHO. Traditional Medicine 2003. Availble from: http://www.who.int/mediacentre/fa ctsheets/fs134/en/. Accessed on: 20 Oktober 2011.

4. Tjahajani A, Widurini. "Aloe vera leaf anti Inflamation's activity speeds up the healing proccess of oral mucosa ulceration". Jakarta : Journal of Dentistry Indonesia; 2011. p: 17-20.

5. Christian A. Sewta, et al. "Pengaruh Pemberian Ekstrak Daun Lidah Buya (Aloe vera L.) Terhadap Penyembuhan Luka Insisi Kulit Kelinci (Oryctolagus cuniculus)". Manado : Jurnal eBiomedik (eBm); 2015. p: 453-459.

6. Nazir. Farhan, et al. "Pengaruh Pemberian Gel Lidah Buaya (Aloe vera) Terhadap Jarak Pinggir Luka pada Tikus Wistar". Padang: Jurnal Kesehatan Andalas; 2015. p: 825834.

7. Rienda Monica Novyana, Susianti. "Lidah Buaya (Aloe vera) untuk Penyembuhan Luka". Majority: 2016. p: 149-153.

8. Campelo AP, et al. "An optimized animal model for partial and total skin thickness burns studies". Article Federal University of Ceara (UFC). Vol. 26 (Suppl. 1) 2011; P: 38-41. Available from : https://www.ncbi.nlm.nih.gov/pub med/21971655 
9. Priscilla Levina. "Perbandingan Efektivitas Aplikasi Topikal Lidah Buaya (Aloe vera), Madu (Apis mellifera), dan Kombinasi Keduanya terhadap Penyembuhan Luka Sayat pada Kulit Mencit (Mus musculus)". Makasar; Skripsi Fakultas Kedokteran Gigi UNHAS: 2017. p : 43-63.

10.Pankaj, Sahu, et al. "Therapeutic And Medicinal Uses Of Aloe Vera: A Review". India : Farmakologi dan Terapi ; 2013. p: 599-610.

11.Hamid A, Soliman M.. "Effect of topical aloe vera on the process of healing of full-thickness skin burn: a histological and immunohistochemical study". Journal of Histology \& Histopathology; 2015. p:1-9.

12.Utami SM, Denanti IR. "Uji Efektivitas Antibakteri Sedian Sabun Cair Cuci Tangan Dari Lendir Lidah Buaya (Aloe vera) Terhadap Eschericia Coli Dan Staphylococcus Aureus". Edu
Masda Journal, 2018; 2( 2); p: 63 72.

13.Ariyanti, NK. "Daya hambat kulit daun lidah buaya (Aloe barbadensis Miller) terhadap pertumbuhan bakteri Staphylococcus aureus ATCC 25923 dan Escherichia coli ATCC 25922". Universitas Udayana: Volume XVI No.1 juni 2012.

14. Mayasari Ayu. "Pengaruh Aplikasi Ekstrak Daging Lidah Buaya Terhadap Jumlah Neutrofil Pada Gingivitis”. Banda Aceh: Skripsi Fakultas Kedokteran Universitas Syiah Kuala: 2016. p: 26-39. 
